\title{
Architecture_MPS
}

\section{Computation and the Impact of New Technologies on the Photography of Architecture and Urbanism}

Mitchell Schwarzer ${ }^{1}$

How to cite: Schwarzer, M. 'Computation and the Impact of New Technologies on the Photography of Architecture and Urbanism.' Architecture_MPS, 2017, 11(1): 4. DOI: https://doi.org/10.14324/111.444.amps.2017v11i4.001.

Published: 01 April 2017

\section{Peer Review:}

This article has been peer reviewed through the journal's standard double blind peer-review, where both the reviewers and authors are anonymised during review.

\section{Copyright:}

(C) 2017, The Author(s). This is an Open Access article distributed under the terms of the Creative Commons Attribution License (CC-BY) 4.0 https://creativecommons.org/licenses/by/4.0/, which permits unrestricted use, distribution and reproduction in any medium, provided the original author and source are credited • DOI: https://doi.org/10.14324/111.444.amps.2017v11i4.001.

\section{Open Access:}

Architecture_MPS is a peer-reviewed open access journal. 


\title{
Title: Computation and the Impact of New Technologies on the Photography of Architecture and Urbanism
}

\section{Author: Mitchell Schwarzer}

\section{Architecture_media_politics_society. vol.11, no.4.}

April 2017

Affiliation: California College of the Arts

\begin{abstract}
Over the course of history, the meanings of buildings have repeatedly been expanded and altered via the creation of technologically driven information realms. In the mid-nineteenth century, for example, the new technology of the photographic camera added informational supplements to the built world not previously known. With greater visual verisimilitude and more popular reach than drawings, photographic images constructed off-site, mediated zones of built and urban appearance, situated not on streets but atop streets on billboards, inside of buildings on gallery walls and, most of all, on printed texts. Since their inception photographic images have recorded the vagaries of the modern built condition, and highlighted what the human eye does not normally notice.
\end{abstract}

In the twentieth century, the influence on architectural understanding of this "visioning technology" was catapulted into even more distant and disembodied information realms through digital technologies. This has taken multiple forms. Satellite imagery, following the trend set by aerial photography, has vaulted human perception to points of distance people had previously only dreamed about. Computation, by contrast, has constructed a portable zone of calculation, memorization, and storage that has amplified the human mind into a societal brain - a garden of mathematically derived outlooks.

Satellite imagery offers faraway views that picture buildings within larger urban and natural contexts that help detect the traces of vanished structures, and provide a digital framework for 


\section{Amps}

imaginings of ideal, future cities. In linked grids, they constitute the foundation for the interactive and virtual photographic explorations common on websites such as Google Earth. By contrast, the digital camera phone in conjunction with photo-sharing websites has unleashed a flood of picture taking, sharing and viewing that in turn has yielded an enormous database available for computational analysis. The millions of uploaded pictures are accompanied by metadata geographic location, time of upload, tag-name of photo - which can be mined algorithmically by computer scientists to uncover the proclivities and itineraries of the general public. Taking on these two distinct aspects of how new digital technologies have influenced our creation, perception, and use of images we previously defined simply as "photographs" - and their influence on our reading of the spaces and places we inhabit - this paper selects just two of the various strands of this new phase of digital photographic imaging. It does so in the belief that these two particular, if unrelated phenomena, reveal their own particular insights into how the digital image may today, interact with our conceptualization of architectural forms and urban spaces. 


\title{
Title: Computation and the Impact of New Technologies on the Photography of Architecture and Urbanism
}

\author{
Author: Mitchell Schwarzer
}

Architecture_media_politics_society. vol. 11, no. 4 .

April 2017

Over the course of history, the meanings of buildings have repeatedly been expanded and altered via the creation of technologically driven information realms. In the mid-nineteenth century, for example, the new technology of the photographic camera added informational supplements to the built world not previously known. With greater visual verisimilitude and more popular reach than drawings, photographic images constructed off-site, mediated zones of built and urban appearance, situated not on streets but atop streets on billboards, inside of buildings on gallery walls and, most of all, on printed texts. Since their inception, photographic images have recorded the vagaries of the modern built condition, ${ }^{1}$ and highlighted what the human eye does not normally notice. ${ }^{2}$

In the twentieth century, the influence on architectural understanding of this "visioning technology" was catapulted into even more distant and disembodied information realms through digital technologies. This has taken multiple forms. Satellite imagery, following the trend set by aerial photography, has vaulted human perception to points of distance people had previously only dreamed about. Computation, by contrast, has constructed a portable zone of calculation, memorization, and storage that has amplified the human mind into a societal brain - a garden of mathematically derived outlooks.

Satellite imagery offers faraway views that picture buildings within larger urban and natural contexts that help detect the traces of vanished structures, and provide a digital framework for imaginings of ideal, future cities. In linked grids, they constitute the foundation for the interactive and virtual photographic explorations common on websites such as Google Earth. By contrast, the digital camera phone in conjunction with photo-sharing websites has unleashed a flood of picture taking, sharing and viewing that in turn has yielded an enormous database available for computational analysis. The millions of uploaded pictures are accompanied by metadatageographic location, time of upload, tag-name of photo - which can be 


\section{Amps}

mined algorithmically by computer scientists to uncover the proclivities and itineraries of the general public. Taking on these two distinct aspects of how new digital technologies have influenced our creation, perception, and use of images we previously defined simply as "photograph" - and their influence on our reading of the spaces and places we inhabit - this paper selects just two of the various strands of this new phase of digital photographic imaging. It does so in the belief that these two particular, if unrelated phenomena, reveal their own particular insights into how the digital image may today, interact with our conceptualization of architectural forms and urban spaces.

\section{Satellite Imagery and Aerial Sensing}

In many ways a historical precedent for the cultural impact of the digital satellite image is the altered venues, modes and meanings of architectural and urban photography produced through the technological impact of aviation. ${ }^{3}$ Whether in their historic or contemporary form, vertical aerial photographic images taken with a lens positioned perpendicular to the ground expose exterior outlines, akin to an architect's floor plans and site plans, while interior spatial divisions are normally hidden by the roof, or fifth façade. Oblique, or bird's-eye images preserve a sense of building mass, but similarly merge or dissolve a building's separate identity - and even those of neighborhoods, infrastructures, cities, and regions - into larger wholes. Both turn buildings into fragments, like the projections of a drawing, which resolve into greater patterns. ${ }^{4}$ Architecture and its context now become inseparable as buildings morph into landscape elements and signs of the architect's creative role diminish.

As has been often the case with new technologies, aerial (and later satellite) photography began with military aims, migrated to civilian and cultural uses, and eventually found commercial applications. ${ }^{5}$ Ensuing photographic and digital image studies gleaned information from patterns made by crops, soil types, shadows and snow, visualizing markings that could be studied for abnormalities that in turn revealed the presence of long-buried buildings or infrastructures. ${ }^{6}$ Such techniques provide an investigative tool for locating the subtle signs of human construction in places that appear at ground level to lack human presence. ${ }^{7}$

The aerial image also provided a rationale for the future appearance of buildings and cities. Since vertical aerial photographs flatten architectural and infrastructural elements, they resemble the graphic projections of cartography. The urbanized region emerges as an intricate network structure feeding built and open space nodes: thicker and thinner lines; longer and shorter lines; straight and curving lines; extra-large, large and small planes of varied shapes. ${ }^{8}$ Illuminating the overall structure of an urban region, aerial imagery did, and still does, help diagnose healthy conditions from maladies, areas for preservation and zones - marked by vacant or "outmoded" structures - needing development or redevelopment. ${ }^{9}$ Like imaginary drawings of 


\section{Amps}

the pre-aerial age, but now powerfully imbued with the "reality effect," these images have, since their inception, enabled architects to visualize the parameters for design before setting foot on a site - inaugurating a process whereby design was distanced from physical place. ${ }^{10}$

Although these processes were existent prior to the digital imagery of satellites, it became the almost exclusive domain of the digital age from 1972 when all-inclusive satellite mapping began with the LANDSAT program. At altitudes between 700 and 900 kilometers above the surface of the earth, the satellites have taken millions of photographic images. ${ }^{11}$ Such repeated and standardized observations of the globe have yielded comparative data on seasonal changes in vegetation and hydrology as well as rough settlement patterns and energy usage, as measured in nocturnal illumination. ${ }^{12}$ These measurements and interpretations were made possible by a parallel satellite effort concerned with positioning. In the greatest navigational advance since the compass and sextant, the NAVSTAR Global Positioning System, launched in 1978 by the US Department of Defense and fully operational by 1995, has allowed land, sea and airborne users to determine their location with respect to latitude, longitude and altitude. ${ }^{13}$

After 1965 satellite photography began to use the new technology of digital imaging: computers processed the scanned, pixelated data for screen viewing. Before digital cameras were sold to the public in the late 1980s, pixels (or picture elements) had already become the grid upon which satellite images were constructed. Not only was the image pixelated, but so too the surface of the planet became an interactive drawing board, each square foot, so to speak, taking the form of a box that could represent different values. Whereas analogue aerial photography revealed buildings as organs connected to circulatory systems, digital satellite sensors turned all elements of the pictorial field into cellular units whose appearance could reflect a variety of values, scales, and temporalities through visible as well as invisible (radio, infrared, ultraviolet, $\mathrm{x}$-ray) electromagnetic evidence.

Toward the end of the millennium, this extraordinary complex of visual data was made available for civilian use, and with the onset of Google Earth in 2005, imagery shot, scripted, controlled, and managed by governmental and corporate entities found an outlet for public viewing. First called Earth Viewer, Google Earth assembled both satellite and aerial digital images into a mirrored reflection of the globe, searchable with place terms and, most amazingly, pan-able across its reaches and zoom-able from satellite views as far as 16,000 kilometers in space to close-up aerial shots that can make out objects as small as 15 meters across. ${ }^{14}$ An interactive, synoptic platform for visualizing the earth's complete natural and built environment was born. ${ }^{15}$

Photographs of individual buildings, published in books or magazines or shown in exhibitions, had long ago familiarized the public with monumental architecture across the globe. Now, via aerial digital imagery, practically everywhere, practically all buildings, all cities, all settlements, all roads, all things became easily accessible. Even nowhere acquired a place on the screen 


\section{Amps}

and our viewing field. ${ }^{16}$ Of course, Google Earth cannot offer an Archimedean view of the entire planet in a range of detail and in the moment of observation or at any historical time period. The website is more of a mosaic than a uniform, real-time picture. Some places, like North Korea, are largely blank. Not all urban areas can be zoomed into at sufficient closeness to observe architectural details. Images taken from different satellites and aircraft come with different resolutions. The digital images one smoothly glides over, or into and out of, encompass a wide temporal range, sometimes as great as five years or more. Google Earth has simulated the built real within a framework of substantial, if often unnoticed differences.

Nonetheless, the fact that one can move across the digital image space of the earth's urbanized regions, and easily dive in or out for more detailed or more comprehensive perusals, represents an extraordinary advance in our ability to engage visually with far-off buildings and urban elements. Such encounters are also social. Google Earth soon included an interactive forum for posting placemarks, comments, and other digital images. In transformative moments, due to fire, flooding, earthquakes or wartime destruction, the system has overlaid new digital imagery spreads alongside the standard view. ${ }^{17}$ In 2007, Google launched Street View, using a fleet of vans, trucks and boats to shoot sites and building elevations the way people see them at ground level. ${ }^{18}$ Part map, part digitized image archive, part video game, the Google Earth experience, as architect Laura Kurgan observes, "takes us beyond Powers of Ten on our desktops. It is not only about understanding the universe across a set of scales. Google Earth, although it might seem to offer a synoptic or even panoptic aerial view of the earth, in fact remains content simply to provide a platform for users to annotate its images. The total map, such as it is, remains well hidden." 19 Indeed, as has been the case with astronomers using the vast image archive of the Sloan Digital Sky Survey, it would seem that the activity of visualizing the built environment is being transformed from one of primarily taking pictures to one of analyzing, comparing, and contrasting the pictures already in the database - and not just that of Google Earth alone, but of the entire surface and deep web.

\section{Photo-Sharing and Big Data}

Concomitant to the developments described so far in the emergence and consequences of satellite imagery, has been a shift from prints and paper to bytes and files, from the darkroom to Photoshop post-production manipulation. It is a shift that has prompted a thoroughgoing reconsideration of photography's documentary status..$^{20}$ The digital image, according to art historian Claire Zimmerman, "now equalizes the real and the imaginary, creating a different condition of being, in which the very idea of 'reality' beyond the surface of the image and its cognitive reception has been effectively canceled." ${ }^{21}$ Instead of seeing their identity in taking portraits of buildings and the urban landscape, photographers increasingly speak of instigating expressive dialogues between 


\section{Amps}

those architectural works and the "architecture" of the digital image. "We no longer take pictures," says architect and writer Pedro Gadanho, "we make images." 22

Not only has there been an ontological shift, however, the presence of the "images we make" has become ubiquitous. A raft of technological developments, including massive computing power and storage, nearly instantaneous Internet distribution, mobile smart phones equipped with cameras, and photo-sharing websites, have launched the digital image into a medium of everyday observation and communication. It is estimated that close to a trillion such digital images will be made in 2015 - a great many of them uploaded, shared and viewed in the social media. Cameras are everywhere: surveying institutions and businesses, monitoring traffic and streets, reproducing documents, scanning bodies at airports and hospitals, gazing at exo-planets and supernovas, at the ready in our pockets and bags. Alongside numerical, verbal, sound and other visual data, digital images contribute to an information tsunami, whose unit of measure is rapidly scaling up from terabytes to petabytes and, of late, exabytes.

"The genius of information technology," according to philosopher Albert Borgmann, "consists in making information pliable by digitizing it, making it abundantly available by collecting and storing astronomical amounts of it, and putting it at our disposal through powerful processing and display devices." ${ }^{23}$ Looking back, analysis of an analogue photograph consisted of research into its production, its maker, and its cultural and artistic context, alongside painstaking observations of its formal aspects. The characteristics of digital images change the equation. Instead of human perusal of the total image set, impossible as the data sets climb to enormous numbers, analytical algorithms are built to ask precise questions of the data, and search across its reaches to discover meaningful patterns, relationships and structures. ${ }^{24}$

Within the growing field of computer analytics, researchers have begun to study how digital image data sets can yield knowledge on how people see, interact with, and make meaning of architecture and urbanism. The data is readily available. Photo-sharing websites like Facebook, Instagram, Flickr, Panoramio and Pinterest contain a horde of images featuring buildings and urban infrastructure in a variety of guises: primarily backdrops for shots of people; occasionally, highlighted works in their own right. In this sense, the images of architecture and cities on these websites continue the traditions of news reporting where events typically subsume the built environment into background. Yet, quite differently, social media digital images are taken day and night by hundreds of millions of people for individualistic reasons. Some of the shooters are on lengthy tourist itineraries in cities. Others are out on a coffee break from work or aimlessly wandering about town. Rarely are the images commissioned or compensated financially. This imagery of our urban settings is created, shared, annotated, and viewed for purposes of self-expression, imaginative investigation, documentation and, perhaps most of all, the 


\section{Amps}

maintenance of relationships through showing, instead of telling, what one's up to and where one's at. ${ }^{25}$

Rarely do social media digital images merit the attention of advanced visual analysis from architects or architecture critics. In any event, analytics, not analysis, is required to make sense of their overwhelming quantity. In other words, the insights to be gleaned from them have less to do with judgments on shedding light on an architect's ideas than with quantitative assessments of how architecture figures within global socio-geographic patterns of image making.

Smartphones, equipped with GPS devices and linked to the Internet, create the conditions by which raw images can be structured as a database. Each uploaded image reveals a date and time, location coordinates, and the phone number of the creator. Many digital images are tagged with single or multiple words, categorizing them for future searches, and others come with captions, user profiles, and further comments, likes and links. The verbal and numeric information constitutes a data constellation around the digital image from which social analyses can be made of our engagement with our architecture and cities. If images represent buildings, their data represent some of the social dynamics that occur in and around them.

As computer scientists David Crandall and Noah Snavely tell us: "Each of these images is a visual observation of what a small part of the world looked like at a particular point in space and time. It is also a record or where a particular person was at a moment in time, and what he or she was paying attention to." ${ }^{26}$ For instance, analytics connecting the identities of the "images makers" and the buildings they represent yield geographic portraits as to how locals, as opposed to tourists, interact with the districts of a city and its buildings. Such studies of image sequences reveal as well how different types of people move within a city on a given day or week, correlating architectural perception with geographic itineraries. ${ }^{27}$

Since their inception, photographic images have frozen architecture in time, creating a record, if we know when they were taken, of how buildings and cities appeared in the past. Up until now, that record has been spotty with respect to temporal and building coverage. With the technologies of digital images all that is changing.

The billions of digitized images of architecture and cities uploaded to the Internet each day are creating a repository of building and city appearance over what amounts to almost continuous time. It is becoming possible to study how buildings and cities change in granular moments (depending upon the number of pictures taken) over the long span by comparing the time stamps of similar location-based images. Constructing image databases thus offers the possibility for scholarly studies into how architecture functions within the social and ecological context of a city or suburb. ${ }^{28}$

How does the process of construction (or demolition) look like on an hourly or daily basis? Exactly when was a building altered or added onto? How have its neighboring structures fared? Were there periods of neglect, as 


\section{Amps}

measured in physical decay, vandalism or graffiti? Were there fires, demonstrations, police actions, or drug deals? What kinds of people enter and exit the building and occupy the street? How do their numbers change depending on the time of day, month or year? When and how often does it rain? When do leaves fall and form? As Crandall and Snavely write: "Imagine all the world's photos as coming from a 'distributed camera,' continually capturing images all around the world. Can this camera be calibrated to estimate the place and time each of these photos was taken?"29

In addition to studying how the architectural context appeared in the past, algorithms have been developed to examine how architectural landmarks stand out in the public eye. In Crandall and Snavely's 2012 study from data on Flickr, the five most visually documented cities in the world were identified as New York, London, San Francisco, Paris, and Los Angeles. The five most represented landmarks were the Eiffel Tower, Trafalgar Square, the Tate Modern, Big Ben, and the Cathedral of Notre Dame. Three of these landmarks were in London and two in Paris. Despite being captured frequently, the three American cities were visually appreciated less for their singular landmarks than a larger collection of architectural and urban attractions. Of the five landmarks, only one was a recent construction, the Tate Modern, while the others all dated before the twentieth century. Even among the predominantly youthful mobile camera-phone users, history still correlates strongly with landmark. Yet within individual cities there were exceptions, as the Apple Store in New York, known not for its built structure but for its products, ranked among its top five landmarks. Such studies explore the range of factors that establish a landmark: materials, historical legacy, artistic innovations, and brand recognition.

Of course, the look and feel of a place rests on factors broader than a few landmarks. In this vein, computer scientists have asked: what are the geographically informative features of an urban environment? In 2007, researchers created a vocabulary tree in order to identify those architectural features most likely to correlate a building with its locale. ${ }^{30}$ In a related 2012 study, using images from Google Street View, algorithms related various visual elements windows, balconies, street signs, architectural styles - with geo-tags and comments, discovering elements that correlate the look and feel of an image with a particular city and even one of its neighborhoods. Relating subjective perceptions of people with architectural and urban attributes, researchers studied patterns in particular cities and architectural features peculiar to those places. ${ }^{31}$ Elaborately carved doors, balconies or windows with railings and streetlamps on pedestals identified Paris. Within Paris, whether railings appeared in conjunction with balconies or windows further correlated whether the building was located on a boulevard or side street. While arches were found in Paris, Prague, Barcelona and London, double arches were especially rare in London. Interestingly, American cities were harder to identify by such measures of stylistic coherence: the industrial, vehicular inspiration for the cityscape may have introduced too many geographically homogenizing building attributes. 


\section{Amps}

Prior to the digital era when information was relatively sparser, every data point was crucial. Yet, at the same time, the difficulty of accessing data led to the widespread use of samples. Nowadays, with extra-large data sets analyzed by high-speed computation, all data, instead of a sampling, can be used. Nor is there any need to worry about certain data points biasing the overall analysis. What matters is discerning the general trend.

For instance, on many photo-sharing websites, tags are created and affixed by people in ad-hoc ways. That turns out not to be a problem and, surprisingly, yields unanticipated benefits. In return for messiness in the way people label and organize their collections of images of buildings and cities, we gain a richer universe of categories and, by extension, a far more heterogeneous understanding of how buildings are seen, named and further conceptualized (in comments) by people. The messy wealth of search tags allows images to be filtered in far more creative ways. ${ }^{32}$ In 2009, using large data sets, of some two million images, computer scientists sought to correlate landmark buildings (and their most distinctive tags or names) with random tags and then a series of image features. This analysis of classification decisions led to information on which kinds of views constitute iconic views of a specific building, or of a larger locale/city. ${ }^{33}$ Which kinds of architectural experiences cause us to classify a building according to its proper or most distinctive name, its typology, its city, and its status as a landmark? How do views of buildings correlate with the signs and locations we assign to them?

Side-by-side or gridded photographic image display has long allowed art historians to perform on-the-spot visual and historical comparisons, a methodology that the discipline's founders, from Heinrich Woefflin to Alois Riegl to Erwin Panofsky, used to discover broad patterns of stylistic changes in works of art and architecture over the course of thousands of years. Can anything similar be accomplished with huge data sets of digital architectural and urban imagery, substituting data mining algorithms for the laborious analysis required of the human eye and brain? ${ }^{34}$

Alas, the digital image data of buildings and cities created on mobile phones and uploaded to photo-sharing websites is presently structured for computational transmission, storage and display, and only for semantic analysis via human intervention. As we have seen, analytics focus on metadata with respect to these digital images, the words and numbers connected to the visual image - upload dates, tags, geo-locations - that are either binary or capable of being categorized. The raw visual data of a continuous tone image remains difficult to structure into categories that can by graphed and analyzed automatically. Yet, computer scientists are working on methods to construct categories of features within the photographic frame, rather than the metadata around it, allowing them to be selected and then mined for their patterns. With respect to the analytics of Internet-uploaded photography of the built environment, the field of "feature extraction" aims to analyze images directly and automatically. While computers cannot understand what a photograph of a building represents, they can already recognize values like brightness, 


\section{Amps}

saturation and hue, number of edges and orientations, positions of corners, and so on. It is only a matter of time before computers will be able to add to their recall skills and be capable of extracting ever more architectural information from massive data sets, and correlating that information into commentaries of the life of buildings within social ecologies.

\section{Information Explosion}

Since the early twentieth century, information concerning architecture has grown by leaps and bounds. Much of that explosion has been image based first analogue and more recently digital imagery. To understand the ongoing, enhanced image exposure given to works of architecture and urbanism it is crucial to examine allied technologies. Here, this has been focused on satellites and computation. As with other advances in image making, they have broadened the field of who creates images of architecture and cities, the places those images are viewed, and the ways those images are interpreted and assigned meaning.

What Gadanho calls "image makers" today have grown from architectural and artistic photographers to scientific, governmental and corporate documenters and, more recently, the general public. The initial activity of photography, an individual equipped with a machine that could reproduce aspects of buildings and cities to a remarkable "reality" and, through publishing and exhibiting contexts, show that "reality" to others, is an ongoing, vital activity. All the same, this close, sometimes exclusive embrace of image maker, building and viewer has been supplemented in significant ways by automated satellites as well as the uncoordinated hundreds of millions of people who upload to the Internet.

Architectural and urban photographs were once the province of mass media books and magazines and fine arts' galleries and museums. These sites expanded with the advent of digital image making and Internet display. Both satellite images and smartphone/social media images provide two-dimensional renderings (and textual and numerical data) of that world in a proliferating array of formats that can be shown in any number of places. Aerial sensing round the clock and across the globe builds a planetary-scale database of built environmental conditions and transformations. Parallel to this activity, individual shooting and posting onto photo-sharing websites construct an equally massive database of the actions and reactions of ordinary individuals to the built environment.

Interpretive methodologies have changed. Customarily, architectural and urban images tend to be analyzed by art, architectural and photography historians and critics, using methods of formal, iconographic and societal analysis characteristic of those disciplines. Some of those same historians study the aerial imagery of buildings and cities, but cartographers, archaeologists, city planners, and civil and military government employees provide the bulk of analysis of this visually distanced built environment. Their emphasis 


\section{Amps}

shifts from intrinsic building elements to regional ensembles and infrastructural networks, displayed individually or as mosaics, and customarily making use of digital techniques. More recently, computer scientists have been most active in scrutinizing and analyzing the enormous data sets on architecture and cities uploaded to photo-sharing websites, categorizing the accompanying digital images and, in turn, using algorithms to search for patterns within those categories. Information comes less from images themselves than from accompanying verbal and numerical notations that tell us where and when individuals shoot our built environment and how they designate the results. All in all, interpretations, such as the formal analysis of individual images or the analytics correlating photo-sharing to societal attitudes on the built world, position these representative modes within negotiations involving artistic, scientific and humanistic knowledge as well as dynamics centered on social standing, military advantage, and, last but by no means least, monetary profit: data supporting demographic, touristic, and business market research essential to city economies and much else.

What impact has satellite imagery and computation had on architectural and urban creation? From the 1970s through the present, digital image capture from the sky has yielded a more nuanced, information-laden view. It is worth remembering that in the digital age images are increasingly used to visualize so-called, underlying urbanized structure, and have also become a means of comparing the same site from different points in space and time. Digital imagery turns buildings into pieces of an evolving puzzle - the pieces being ongoing natural and societal forces. Google Earth, and other websites similar to it, offer architects and planners a means to reference visual conditions at most urbanized sites in the world, and compare them at different spatial and temporal scales.

Computer scientists may be showing architects another way of sifting through the rapidly growing image database. By exploiting information gleaned from copious images of the built world by the vox populi, they have exposed that public's evolving viewing habits. The numbers of images taken and exhibited are so vast as to dissolve individual responses within quantitative, demographic profiles. Instead of the image maker's or critic's singular voice, computer scientists track the shifting glances and attention spans of an emerging world public, and mainly that youthful segment who snap and post continually. Algorithms uncover those buildings or sites represented most frequently. Most are landmarks propped up by the mass media. But analysis also detects emerging, unpredictable "landmarks," products of a social media aesthetic geared to the overlooked and a marketplace preference for newness. In such studies, architects can gain awareness of how the general public increasingly sees and values the built world and, importantly, how it figures in imagistic constructions of individuality and community.

Given the attention to shooting, uploading and viewing digital images all the time, people may be focusing their looking, communicating and reflecting into viewing corridors conditioned by their actions with respect to 


\section{Amps}

photo-sharing websites, framing the built world through its standards, seeing buildings through the reactions of others - what amounts to an aesthetic of mobile phones. It is possible to conceive that architects could design buildings that respond to or critique image-sharing web appeal, designing with respect to technology's impact on viewing - much the way they have long taken into account the way people see while walking in a lengthy procession or on a much speedier drive in an automobile.

\section{Conclusion}

This article has attempted to demonstrate that the two most important new technologies of the twentieth century, aviation and computation, have promiscuously allied with photography to construct new ways of recording, understanding and interacting with the built world. Digital effects have been central to these endeavors. Aviation first encompassed traditional analogue photography and in the early satellite age went over the new techniques of digital imagery. By that point, computation had already passed into digital practices. Most importantly, digital images taken by orbiting satellites or selfie sticks transformed the uses of architectural and urban photography.

They have created rich phenomenological platforms for experiencing buildings and cities off site - incorporating the passage of time, a scale of viewing positions, geographical fullness, and heightened user interactivity. Encompassing aerial mosaic-images taking in hundreds or thousands of structures that insinuate a distanced perspective, and photo-sharing websites containing tens of millions of images which turn the photography of self and place into elements of everyday communication, the new technological modes of aviation and computation encourage immersive conditions with respect to their photographic-informative simulacra of architecture and urbanism: the inhabitation of virtual-photographic geographies of the built world on the screen; the back and forth actions of shooting, uploading and viewing digital photographs involving buildings and cities on photo-sharing websites. Unlike analogue photographs taken by architectural and artistic photographers, the vast and differentiating database of digital imagery is less of a form of art than a way of life. It is produced by a far larger set of actors, it plays on screens everywhere, and it serves a wide-ranging set of social, political and commercial negotiations.

Taken together, photographs taken by experts on the ground, machines in the sky, and practically everyone from mobile phones appear to be crowding out other forms of architectural information: immediate perception of a building; reflection gained from reading and conversation. They also appear to be challenging the architect's customarily privileged role with respect to shaping our visual approaches and reactions to them. Half a millennium ago, drawing and text were elite technological tools that allowed the development of "architects" from what had been craftsmen and builders. Two centuries ago, the advent of photography constructed a second stage for viewing 


\section{Amps}

buildings, and a second creator, the expert photographer. A century ago, analogue aerial photography began a process leading to a third and quite different creative realm of visual architectural information. And over the past few decades, in aerial/satellite shooting and mobile phone shooting, not to mention other means of digital capture not discussed in this article like surveillance cameras, a far more comprehensive and diffuse creator has emerged. What the history of technological advances tells us, however, is that information realms do not erase one another. Rather, they build upon and into each other, the architect's drawing and text, say, as foundation, the photograph as superstructure, and the interactive aerial/satellite mosaic and popular production of digital imagery as infrastructure.

\section{Notes}

1 Douglas Klahr, "The Elusive Challenge of Photographing Urban Spaces: Nineteenth-Century Berlin as Exemplar," in Nineteenth-Century Photographs and Architecture: Documenting History, Charting Progress and Exploring the World, ed. Micheline Nilsen (Farnham, Surrey: Ashgate, 2013), 167.

2 Martin Caiger-Smith, "Site Work," in Site Work: Architecture and Photography since Early Modernism, eds., Martin Caiger-Smith and David Chandler (London: The Photographer's Gallery, 1991), 7. On the photographic highlighting of hard-to-notice aspects of architecture, see Akiko Busch, The Photography of Architecture: Twelve Views (New York: Van Nostrand Reinhold, 1987), 7-8.

3 Photographs taken from the sky can be traced back to 1859 and Félix Nadar's aerial daguerreotypes of Paris from a balloon and Wilbur Wright's 1909 airplane photographs of Italy. The new aerial shots showcased buildings within larger contexts impossible to perceive at ground level. See the discussion on aerial photography of the built environment in Mitchell Schwarzer, Zoomscape: Architecture in Motion and Media (New York: Princeton Architectural Press, 2004), 118-63.

4 Charlotte Trümpler, "Aerial Photography in Archaeology and its Pioneers," in The Past from Above: Aerial Photographs of Archaeological Sites, ed. Charlotte Trümpler (London: Frances Lincoln Ltd., 2005), 9-20.

5 During the First World War, Theodor Wiegand's survey of archaeological remains across Ottoman Palestine revealed an aerial photograph's ability to record contours (and thus buried building wholes) indecipherable at ground level because of built absences, interruptions or deformations. See Robert Bewley and David Kennedy, "Historical Aerial Imagery in Jordan and the Wider Middle East," in Archaeology from Historical Aerial and Satellite Archives, eds. William Hanson and Ioana Oltean (New York: Springer, 2013), 228.

6 Soil marks exposed underground building walls, because of the fact that soil tends to be deeper over ditches than walls, encouraging more luxuriant growth. Shadow marks cast by slightly projecting walls gave archaeologists enough evidence to search for larger, underground built features. Michael Parrington, "Remote Sensing," Annual Review of Anthropology 12 (1983): 108. 


\section{Amps}

7 In recent years, Unmanned Aerial Vehicles (UAVs), especially multi-bladed helicopters, have augmented manned-aerial photography of archaeological sites. Able to take off and land in enclosed spaces, the drone helicopters can fly at extremely low altitudes and photograph details much closer in than aircraft, and thus achieve perspectives of architecture occluded (by walls or structures) and thus not seen from ground scanning. See Neil Smith, Luca Passone, Daid al-Said, Mohamed al-Farhan, Thomas Levy, "Drones in Archaeology: Integrated Data Capture, Processing, and Dissemination in the al-Ula Valley, Saudi Arabia," Near Eastern Archaeology 77 (September 2014): 176-81.

8 Historically, Le Corbusier's Aircraft (1935) included photographs that illustrated these elemental characteristics of urban landscapes, and associated that knowledge with ideas the architect had already gleaned from abstract art. See Elisa Dainese, "Le Corbusier, Marcel Griaule, and the Modern Movement: Exploring the Habitat from the Airplane," in Envisioning Architecture: Design, Communication, Evaluation, Communication, eds. Eugenio Morello and Barbara Piga (Roma: Edizioni Nuova Cultura, 2013), 413-17.

9 Over time, the aerial photographic perspective became more nuanced to pragmatic planning perspectives, attentive less to a singular logic of urban appearance than to cross-cultural differences in building and habitation. See the discussion on interwar city planning in Jeanne Haffner, The View from Above: The Science of Social Space (Cambridge, MA: MIT. Press, 2014), 19-54.

10 In 1959, the United States launched Corona, the first reconnaissance satellite, followed by the Argon and Lanyard missions. Hundreds of thousands of photographs were taken remotely and surreptitiously, mostly for spying purposes. On the early history of reconnaissance photographs taken from satellites, see Dwayne Day, John Logsdon, and Brian Latell, Eye in the Sky: The Story of the Corona Spy Satellites (Washington, DC: Smithsonian Institution Press, 1998).

11 The current LANDSAT 7 produces a complete set of images of the earth's surface every sixteen days: each image covers approximately 31,000 square kilometers. A. M. Chandra and S. K. Ghosh, Remote Sensing and Geographical Information Systems (Oxford: Alpha Science International Ltd., 2006), 26.

12 Francis Conant, "The Use of LANDSAT Data in Studies of Human Ecology," Current Anthropology 19 (June 1978): 382-4.

13 Originally used for missile guidance, troop location, vehicle navigation, mapping and surveying, assessment of global environmental conditions, public-safety monitoring, and weather forecasting, the GPS became available for civilian use in 2000. Sameer Kumar and Kevin B. Moore, "The Evolution of Global Positioning System (GPS) Technology,” Journal of Science Education and Technology 11.1 (March, 2002): 60-71.

14 The panning function results from altering the flat images via equi-rectangular projection to match the contours of the globe.

15 See Mitchell Schwarzer, "Landscape Navigator: The Experience of Place on YouTube and Google Maps," Harvard Design Magazine 36 (Spring 2013): 136-44.

16 See the discussion of how nowheres everywhere suddenly have a place on the screen in Martin Dodge and Chris Perkins, "The 'View from Nowhere'? Spatial Politics 


\section{Amps}

and Cultural Significance of High Resolution Satellite Imagery," Geoforum 40.4 (July 2009): 497-501.

17 A historical timeline was added in 2009, adding archived imagery of an area.

18 Ben Campkin and Rebecca Ross, "Negotiating the City through Google Street View," in Camera Constructs: Photography, Architecture and the Modern City, eds. Andrew Higgott and Timothy Wray (Farnham, Surrey: Ashgate, 2012), 148-150.

19 Laura Kurgan, "Google Earth 5.0," Journal of the Society of Architectural Historians 68.4 (December 2009): 590.

20 Robert Elwall, Building with Light: The International History of Architectural Photography (London: Merrell Publishers Limited, 2004), 200-1.

21 Claire Zimmerman, Photographic Architecture in the Twentieth Century (Minneapolis: University of Minnesota Press, 2014), 308.

22 Pedro Gadanho, "Coming of Age: On the Furtive, Shifting Nature of Architectural Photography," in Shooting Space: Architecture in Contemporary Photography, ed. Elias Redstone (London: Phaidon, 2014), 228.

23 Albert Borgmann, Holding on to Reality: The Nature of Information at the Turn of the Millennium (Chicago: University of Chicago Press, 1999), 170-1.

24 Lev Manovich, "Watching the World," Aperture 214 (Spring, 2014): 48, 50.

25 Oded Nov, Mor Naaman, and Chen Ye, "Analysis of Participation in an Online Photo-Sharing Community: A Multidimensional Perspective," Journal of the American Society for Information Science and Technology 61.3 (2010): 10.

26 David Crandall and Noah Snavely, "Networks of Photos, Landmarks, and People," Leonardo 44 (June, 2011): 240.

27 Balint Kadar and Matyas Gede, "Where do Tourists Go?: Visualizing and Analyzing the Spatial Distribution of Geotagged Photography," Cartographica: The International Journal for Geographic Information and Geovisualization 48 (Summer 2013): 87.

28 Zhou Bolei, Liu Liu, Aude Oliva, and Antonio Torralba, "Recognizing City Identity via Attribute Analysis of Geo-tagged Images," ECCV [European Conference on Computer Vision] 3 (2014): 519-34.

29 David Crandall and Noah Snavely, "Modeling People and Places with Internet Photo Collections," Communications of the ACM 55.6 (June, 2012): 52-60.

30 Grant Schindler, Matthew Brown, and Richard Szeliski, "City-Scale Location Recognition," IEEE Conference on Computer Vision and Pattern Recognition (2007), 1-7; See also Jan Knopp, Josef Sivic, and Tomas Pajdla, "Avoiding Confusing Features in Place Recognition," ECCV [European Conference on Computer Vision] (2010): 748-61.

31 Carl Doersch, Saurabh Singh, Abhinav Gupta, Josef Sivic, and Alexei Efros, "What Makes Paris Look Like Paris," ACM [Association for Computing Machinery] Transactions on Graphics 31.3 (2012): n.p.

32 Viktor Mayer-Schönberger and Kenneth Cukier, Big Data: A Revolution that Will Transform How We Live, Work and Think (Boston: Houghton Mifflin Harcourt, 2013), 43.

33 Yunpeng Li, David Crandall, and Daniel Huttenlocher, "Landmark Classificiation in Large-Scale Image Collections," IEEE [Institute of Electrical and Electronics Engineers] 12th International Conference on Computer Vision (2009): n.p. 


\section{Amps}

34 On access to and management of large image databases, see Gerald Schaefer and Simon Ruszala, "Effective and Efficient Browsing of Image Databases," International Journal of Imaging Systems and Technology 18 (August 2008): 137-43; Gerald Schaefer, "Interactive Exploration of Image Collections," in Computer Recognition Systems 4, eds. Robert Burduk, Marek Kurzynski, Michal Wozniak, and Andrzej Zolnierek (Berlin: Spring, 2011).

\section{Bibliography}

Bolei, Zhou, Liu Liu, Aude Oliva, and Antonio Torralba. "Recognizing City Identity via Attribute Analysis of Geo-tagged Images." ECCV [European Conference on Computer Vision] 3 (2014): 1-16.

Campkin, Ben, and Rebecca Ross. "Negotiating the City through Google Street View." In Camera Constructs: Photography, Architecture and the Modern City, edited by Andrew Higgott and Timothy Wray, 147-57. Farnham, Surrey: Ashgate, 2012.

Chandra, A. M., and S. K. Ghosh. Remote Sensing and Geographical Information Systems. Oxford: Alpha Science International Ltd., 2006.

Crandall, David and Noah Snavely. "Modeling People and Places with Internet Photo Collections." Communications of the ACM 55.6 (June, 2012): 52-60.

Crandall, David and Noah Snavely. "Networks of Photos, Landmarks, and People." Leonardo 44 (June 2011): 240-3.

Day, Dwayne, John Logsdon, and Brian Latell. Eye in the Sky: The Story of the Corona Spy Satellites. Washington, DC: Smithsonian Institution Press, 1998.

Dodge, Martin, and Chris Perkins. "The 'View from Nowhere'? Spatial Politics and Cultural Significance of High Resolution Satellite Imagery.” Geoforum 40.4 (July 2009): 497-501.

Doersch, Carl, Saurabh Singh, Abhinav Gupta, Josef Sivic, and Alexei Efros. "What Makes Paris Look Like Paris." ACM [Association for Computing Machinery] Transactions on Graphics 31.3 (2012): 103-10.

Elwall, Robert. Building with Light: The International History of Architectural Photography. London: Merrell Publishers Limited, 2004.

Gadanho, Pedro. "Coming of Age: On the Furtive, Shifting Nature of Architectural Photography." In Shooting Space: Architecture in Contemporary Photography, edited by Elias Redstone, 230-3. London: Phaidon, 2014.

Haffner, Jeanne. The View from Above: The Science of Social Space. Cambridge, MA: MIT. Press, 2014.

Kadar, Balint, and Matyas Gede. "Where do Tourists Go?: Visualizing and Analyzing the Spatial Distribution of Geotagged Photography." Cartographica: The International Journal for Geographic Information and Geovisualization 48 (Summer 2013): 1-15.

Kumar, Sameer, and Kevin B. Moore. "The Evolution of Global Positioning System (GPS) Technology." Journal of Science Education and Technology 11.1 (March, 2002): 60-71.

Kurgan, Laura. "Google Earth 5.0.” Journal of the Society of Architectural Historians 68.4. (December 2009): 588-90. 


\section{Amps}

Li, Yunpeng, David Crandall, and Daniel Huttenlocher. "Landmark Classification in Large-Scale Image Collections." IEEE [Institute of Electrical and Electronics Engineers] 12th International Conference on Computer Vision (2009): n.p.

Nov, Oded, Mor Naaman, and Chen Ye. "Analysis of Participation in an Online Photo-Sharing Community: A Multidimensional Perspective." Journal of the American Society for Information Science and Technology 61.3 (2010): 555-66.

Schwarzer, Mitchell. "Landscape Navigator: The Experience of Place on YouTube and Google Maps." Harvard Design Magazine 36 (Spring 2013): 136-44.

Schwarzer, Mitchell. Zoomscape: Architecture in Motion and Media. New York: Princeton Architectural Press, 2004.

Schindler, Grant, Matthew Brown, and Richard Szeliski. "City-Scale Location Recognition." IEEE Conference on Computer Vision and Pattern Recognition (2007): n.p.

Zimmerman, Claire. Photographic Architecture in the Twentieth Century. Minneapolis: University of Minnesota Press, 2014. 